\title{
Pancreatic adenocarcinoma: update on the surgical pathology of carcinomas of ductal origin and PanINs
}

\author{
Ralph H Hruban ${ }^{1}$ and Noriyoshi Fukushima ${ }^{2}$ \\ ${ }^{1}$ Departments of Pathology and Oncology, The Sol Goldman Pancreatic Cancer Research Center, The Johns \\ Hopkins Medical Institutions, Baltimore, MD, USA and ${ }^{2}$ The Department of Pathology, University of Tokyo, \\ Tokyo, Japan
}

\begin{abstract}
Pancreatic cancer is the fourth leading cause of cancer death in the US. Most pancreatic cancers are infiltrating ductal adenocarcinomas. The careful application of well-defined morphologic criteria can be used to differentiate between infiltrating ductal adenocarcinoma and reactive glands. While most pancreatic cancers are ductal adenocarcinomas, a number of histologically defined variants have been described. These are important to recognize because they have distinct clinical pathologic features. Pancreatic intraepithelial neoplasia (PanIN) is the presumed precursor lesion to infiltrating ductal adenocarcinoma, and PanIN lesions can mimic infiltrating cancer.
\end{abstract}

Modern Pathology (2007) 20, S61-S70. doi:10.1038/modpathol.3800685

Keywords: pancreatic cancer; pancreas; precursor; pancreatic intraepithelial neoplasia

Infiltrating ductal adenocarcinoma of the pancreas (pancreatic cancer) is one of the most lethal of all of the solid malignancies. ${ }^{1}$ Last year 33,730 Americans were diagnosed with pancreatic cancer, and 32,300 died from it, making pancreatic cancer the fourth leading cause of cancer death. ${ }^{1}$ Worldwide it is estimated that 213,000 will die from pancreatic cancer. ${ }^{2}$ These numbers will only grow as the population ages.

Pancreatic cancer can be hard on the pathologist. The stakes are high and the diagnoses are difficult. Both the life expectancy and the most appropriate treatment for a patient diagnosed with chronic pancreatitis differ significantly from the life expectancy and appropriate treatment for a patient diagnosed with pancreatic cancer. Yet, in some cases, it can be extremely difficult, if not impossible, to distinguish histologically between a benign reactive gland of chronic pancreatitis and an infiltrating gland of well-differentiated pancreatic cancer.

Here, we outline well-defined morphologic criteria that can be used to differentiate between neoplastic and reactive glands. In addition, the clinical

Correspondence: Dr RH Hruban, MD, Departments of Pathology and Oncology, The Sol Goldman Pancreatic Cancer Research Center, Weinberg 2242, 401 North Broadway, Baltimore, MD 21231-2410, USA.

E-mail: rhruban@jhmi.edu

Received 18 July 2006; accepted 26 July 2006 characteristics, morphologic spectrum, and grading of infiltrating ductal adenocarcinoma will be presented. Emphasis will be placed on precursor lesions, called 'pancreatic intraepithelial neoplasia (PanIN)', because these lesions can mimic infiltrating cancer, and because a better understanding of these lesions offers the best hope for treating pancreatic neoplasia before an incurable invasive cancer develops. ${ }^{3}$

\section{Ductal adenocarcinoma}

Infiltrating ductal adenocarcinoma of the pancreas is an invasive malignant epithelial neoplasm with glandular (ductal) differentiation and without a predominant component of any other type of carcinoma. ${ }^{4-7}$ Most pancreatic cancers are diagnosed between the ages of 60 and 80 years. ${ }^{8}$ Although uncommon, pancreatic cancer can, and does, occur in individuals younger than 40 years of age. ${ }^{9}$ Cigarette smoking, a family history of pancreatic cancer, diabetes mellitus and obesity are all wellestablished risk factors. ${ }^{10,11}$ Most patients do not develop symptoms until after the cancer has metastasized, and many patients are not correctly diagnosed until many months or even years after they first develop symptoms. ${ }^{7}$ As a result, only $20 \%$ of patients are surgical candidates at the time of diagnosis. Common presenting symptoms include 
epigastric pain that radiates to the back, unexplained weight loss, painless jaundice, light claycolored stools, dark urine, pruritus, nausea, and $10 \%$ develop spontaneously appearing and disappearing thromboses. ${ }^{7,12,13}$ New onset diabetes mellitus in an older patient is an early sign of the disease in some patients. ${ }^{14}$ Unfortunately, there are no effective screening tests for early asymptomatic disease.

Grossly, most infiltrating ductal adenocarcinomas form poorly defined firm fibrotic masses (Figure 1). They are white-yellow, and they obscure the normal lobular architecture of the pancreas. ${ }^{7}$ This latter feature can be very helpful in distinguishing between chronic pancreatitis and infiltrating ductal adenocarcinoma. Some cancers undergo central necrosis and these cancers can form gross cysts (Figure 2). Cysts may also be found adjacent to the carcinoma due to localized dilatation of obstructed ducts (retention cysts). ${ }^{7}$

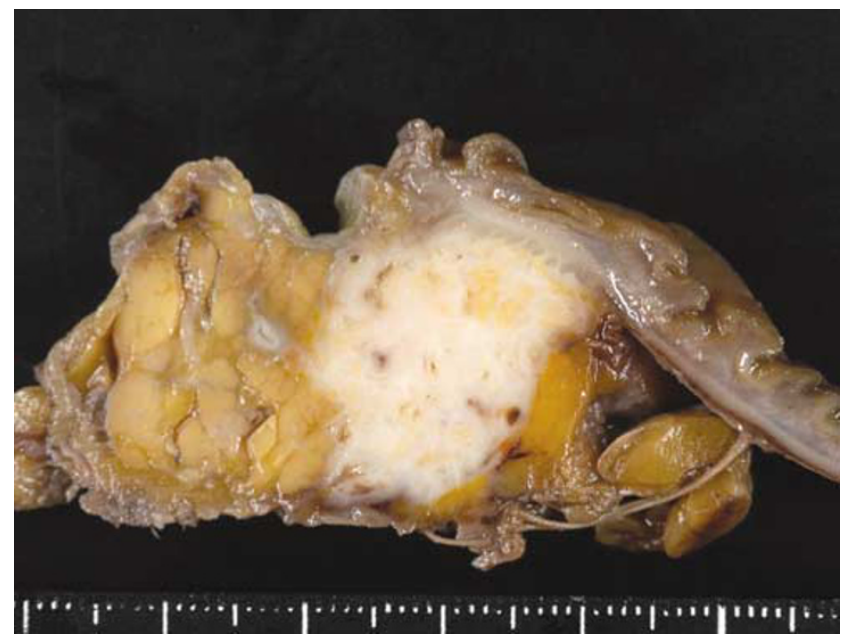

Figure 1 Cross-section of an infiltrating ductal adenocarcinoma.

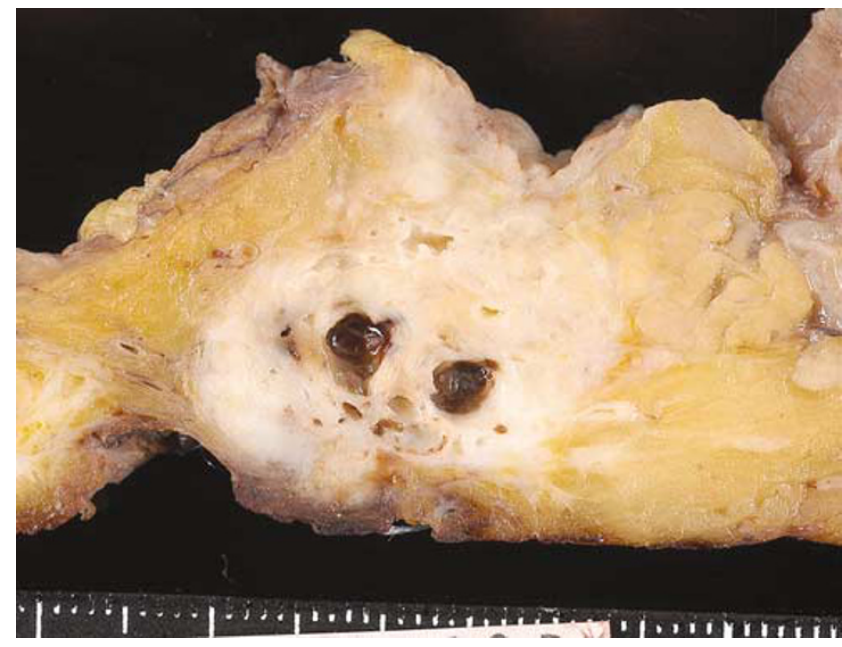

Figure 2 Infiltrating adenocarcinoma with focal cystic degeneration.
Microscopically, as defined above, infiltrating ductal adenocarcinoma of the pancreas is an invasive malignant epithelial neoplasm with glandular (ductal) differentiation and without a predominant component of any of the other carcinoma types. ${ }^{4-7,12,15}$ The degree of gland formation can vary from well-formed glands, to partially formed glands, to focal intracellular mucin production by poorly oriented cells infiltrating singly, to solid sheets of neoplastic cells. ${ }^{7}$ Several features can be used to distinguish between benign reactive glands and infiltrating ductal adenocarcinoma, and most of these boil down to location (Table 1). In evaluating the location of a duct, recall that non-neoplastic glands, even when there is severe chronic pancreatitis, form predictable lobular units. The ducts are towards the center of the lobular unit and are surrounded by grape-like clusters of acini.

The first feature useful in establishing a diagnosis of pancreatic cancer is that pancreatic carcinoma infiltrates in a haphazard pattern (Figure 3). The glands violate the lobular architecture, and are strewn in the parenchyma without rhyme or reason. Second, and this really is a manifestation of the first

Table 1 Hematoxylin and Eosin features useful in distinguishing benign glands and invasive adenocarcinoma ${ }^{\mathrm{a}}$

\begin{tabular}{lll}
\hline & Benign gland & Invasive carcinoma \\
\hline Haphazard growth pattern & No & Yes \\
Glands adjacent to vessels & No & Yes \\
Perineural invasion & No & Yes \\
Intravascular invasion & No & Yes \\
Nuclear variation $>4$ to 1 & No & Yes \\
Intraluminal necrosis & Usually no & Often \\
Incomplete glands & No & Often \\
Gland touching fat & No & Yes \\
\end{tabular}

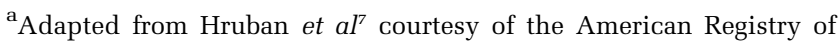
Pathology.

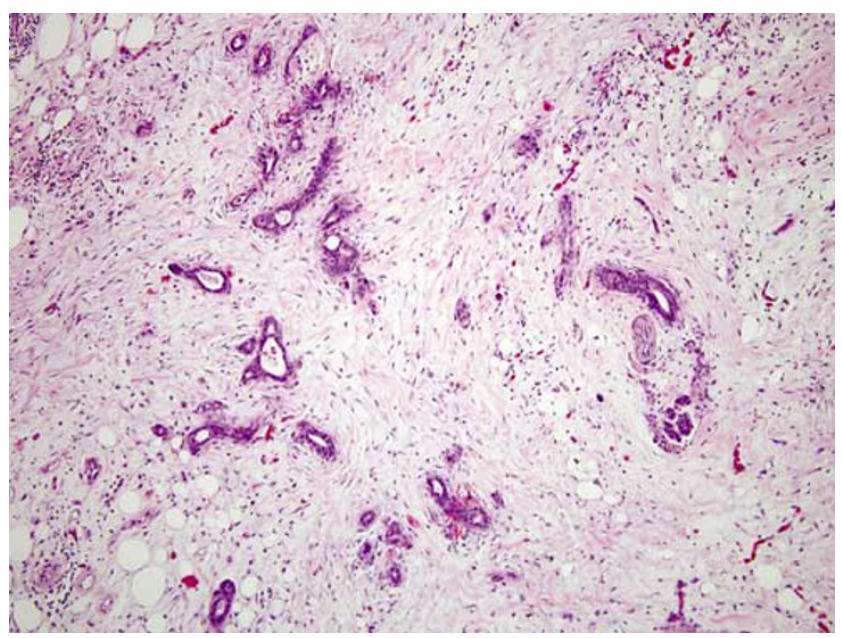

Figure 3 Haphazard growth pattern of an infiltrating ductal adenocarcinoma. 


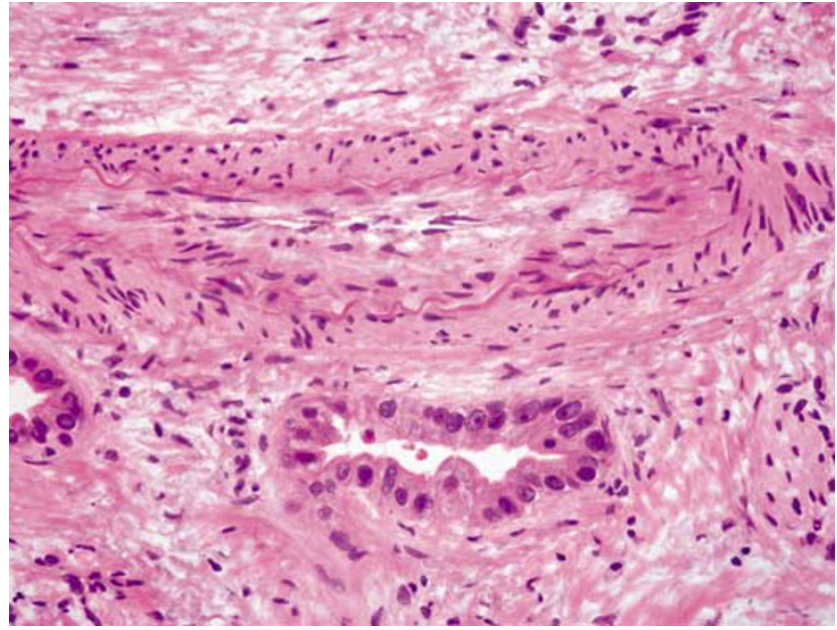

Figure 4 Gland adjacent to a muscular vessel in an infiltrating ductal adenocarcinoma.

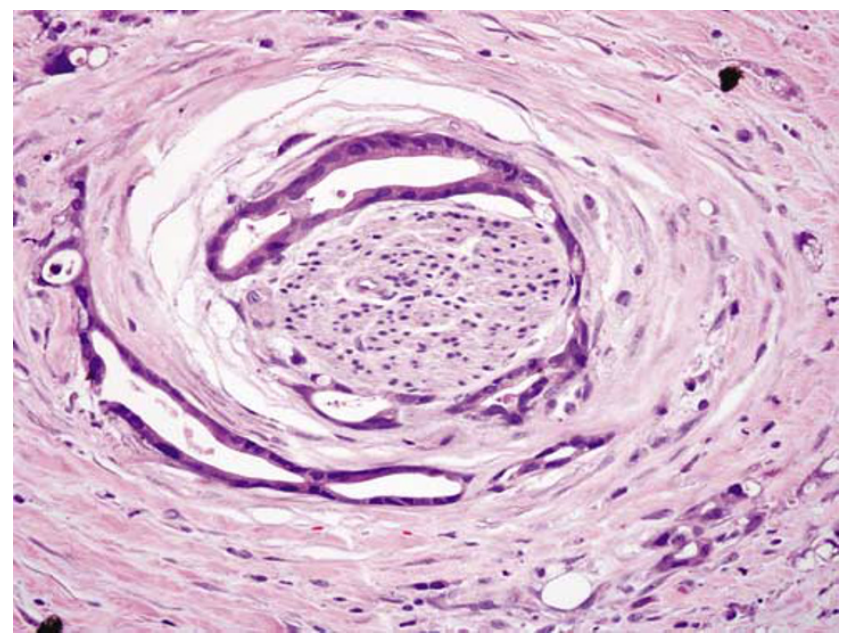

Figure 5 Perineural invasion in an infiltrating ductal adenocarcinoma.

feature, is that neoplastic glands can be found adjacent to muscular arteries without intervening pancreatic parenchyma (Figure 4). ${ }^{16}$ By contrast, in the non-neoplastic pancreas, muscular arteries run at the periphery of the lobules separated from the ducts by pancreatic parenchyma. The third and fourth features of invasive ductal adenocarcinoma are that glands will be found where they simply do not belong. Perineural and vascular invasion are both features of an invasive adenocarcinoma (Figures 5 and 6). Benign glands abutting a nerve have been reported in extremely rare instances of severe chronic pancreatitis, ${ }^{17}$ but true perineural invasion is virtually diagnostic of invasive pancreatic cancer. ${ }^{18-21}$ One feature of vascular invasion that should be noted is that when pancreatic cancer infiltrates into vessels it has a tendency to grow along the intimal surface of the vessel. In these instances the malignant glands lining the intima of

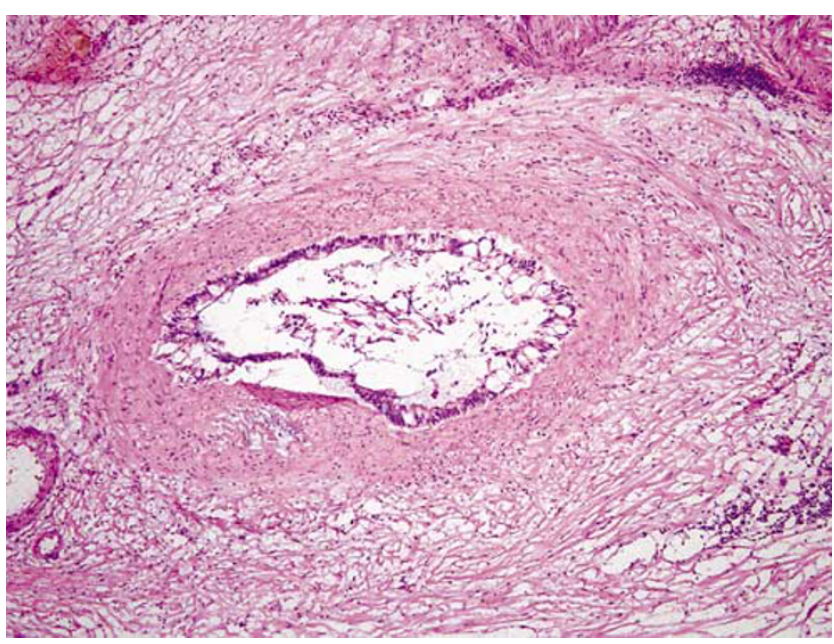

Figure 6 Intravascular invasion. This pattern can mimic a PanIN lesion.

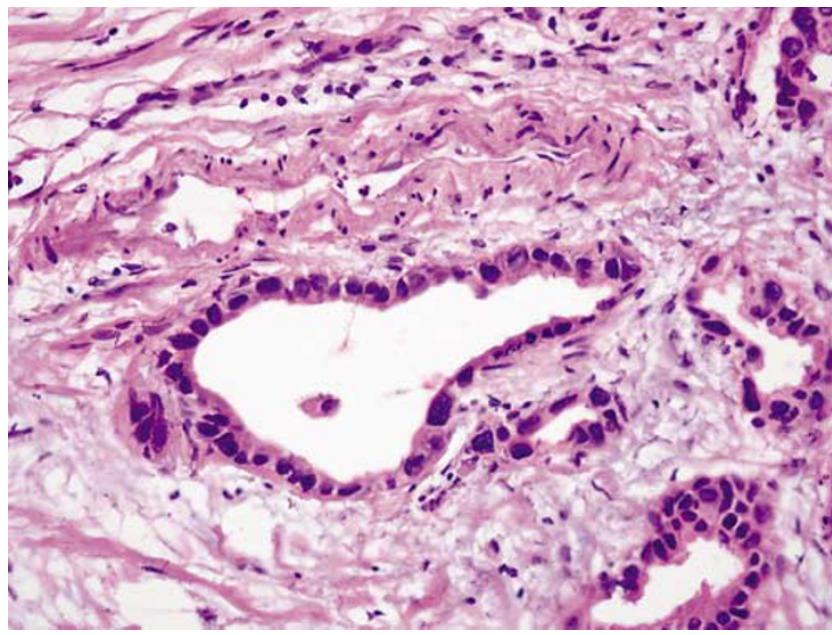

Figure 7 The four to one rule in an infiltrating ductal adenocarcinoma. Note that the atypical gland is also adjacent to a muscular vessel.

the vessel can mimic a low-grade pancreatic intraepithelial neoplasia (PanIN) lesion (Figure 6). The fifth feature is called the ' 4 to 1 rule'. The nuclei in non-neoplastic glands tend to be uniform, and in a single gland the area of the nuclei do not vary by more than 4 to 1 (Figure 7). By contrast, significant nuclear pleomorphism can be seen in ductal adenocarcinomas, and the finding of nuclei in a single gland varying in area by more than 4 to 1 is indicative of a malignancy. Necrotic debris within the lumen of a gland is the sixth feature to support a diagnosis of pancreatic cancer. The seventh feature is incomplete lumina-that is lumina which are not completely lined by an epithelial layer such that the luminal contents appear to directly touch the stroma. We find the eighth feature, a gland directly touching fat without intervening stroma, difficult to apply. The ninth and final feature is the immunolabeling profile (Table 2). The expression of the 
DPC4/MADH4 gene product, dpc4, is completely lost in $55 \%$ of infiltrating ductal adenocarcinomas (Figure 8), and cancers express carcinoembryonic antigen (CEA) and mesothelin. By contrast, the vast majority of non-neoplastic glands have intact (normal) labeling for dpc4 and most do not express

Table 2 Immunohistochemical staining in the diagnosis of ductal adenocarcinoma $^{\mathrm{a}}$

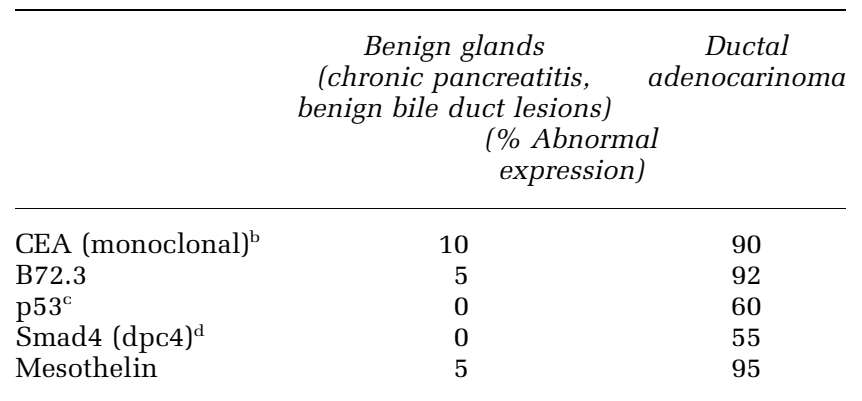

${ }^{\mathrm{a}}$ Adapted from Hruban et $a l^{7}$ courtesy of the American Registry of Pathology.

${ }^{\mathrm{b}}$ Abnormal expression is cytoplasmic reactivity.

${ }^{\mathrm{c}}$ Abnormal expression is reactivity in $>20 \%$ of nuclei.

${ }^{\mathrm{d}}$ Abnormal expression is loss of cytoplasmic and nuclear activity.

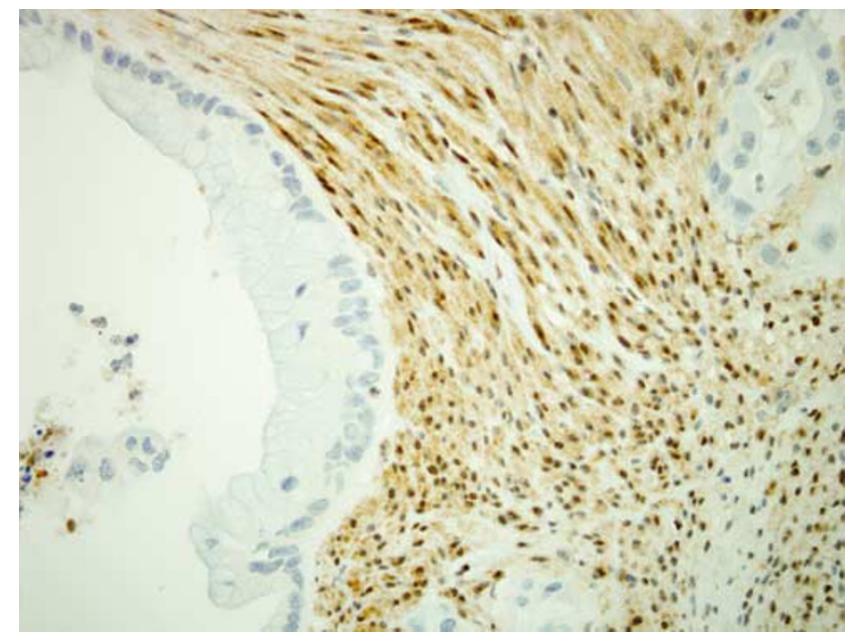

Figure 8 Loss of Dpc4 expression in an infiltrating ductal adenocarcinoma.
CEA or mesothelin. When rigorously applied, these nine features form a solid foundation for one of the most difficult differential diagnosis in surgical pathology, namely chronic pancreatitis vS pancreatic cancer.

Infiltrating ductal adenocarcinoma can be histologically graded (Table 3 ), although the grading has only minimal prognostic significance. ${ }^{7}$ Well-differentiated adenocarcinomas form well-defined glands. ${ }^{4-7}$ The glands are typically complete, and the neoplastic cells are cuboidal to columnar with basally oriented uniform round to oval nuclei with evenly dispersed chromatin. ${ }^{7}$ Only minimal nuclear pleomorphism is seen. Mitotic figures can be seen, but are not numerous, nor are they atypical.

The gland formation in moderately differentiated adenocarcinoma is less well-defined. ${ }^{4-7}$ Incomplete glandular lumina are common, as is nuclear pleomorphism. The nucleoli are larger and more irregular, and mitoses are more common, and may be atypical. $^{7}$

Poorly differentiated adenocarcinomas are composed of poorly formed glands, with individual infiltrating cells and solid areas. ${ }^{4-7}$ The neoplastic cells produce significantly less mucin than the better differentiated pancreatic cancers. Nuclear pleomorphism is prominent with large bizarre nuclei and the nucleoli are large, multiple and more irregular. ${ }^{7}$ Mitoses, including atypical mitoses, are common. The grading system developed by Klöppel incorporates the degree of glandular differentiation, mucin production, nuclear atypia and the mitotic count (Table 3). ${ }^{22}$ More recently, Adsay has proposed a simpler grading system that parallels the Gleason grading system for prostate cancer. ${ }^{23}$ Pancreatic cancers commonly have a combination of well-formed glands as well as individual cells and clusters, resulting in the appearance of both welldifferentiated and poorly differentiated elements in the same carcinoma. In these cases, the carcinoma should be assigned the worst degree of differentiation present in a significant portion of the carcinoma. $^{7}$

Special stains and immunohistochemical labeling can help in the evaluation of suspected infiltrating ductal adenocarcinoma. Most adenocarcinomas of

Table 3 Histologic grading of pancreatic cancer ${ }^{22}$

\begin{tabular}{lllll}
\hline Tumor grade & Glandular differentiation & $\begin{array}{l}\text { Mucin } \\
\text { production }\end{array}$ & $\begin{array}{c}\text { Mitoses } \\
\text { (per 10 hpf) }\end{array}$ & Nuclear atypia \\
\hline 1 & Well-differentiated duct-like glands & Intensive & $\leq 5$ & $\begin{array}{l}\text { Little pleomorphism, polar } \\
\text { arrangement }\end{array}$ \\
2 & $\begin{array}{l}\text { Moderately differentiated duct-like structures } \\
\text { and tubular glands }\end{array}$ & Irregular & $6-10$ & Moderate pleomorphism \\
3 & $\begin{array}{l}\text { Poorly differentiated glands, muco-epidermoid } \\
\text { and pleomorphic structures }\end{array}$ & Abortive & $>10$ & $\begin{array}{l}\text { Marked pleomorphism and increased } \\
\text { nuclear size }\end{array}$
\end{tabular}


Table 4 Genetic alterations in pancreatic cancer ${ }^{\mathrm{a}}$

\begin{tabular}{|c|c|c|c|c|}
\hline Type of gene & Gene & Chromosome & Mechanism of alteration & $\%$ Of cases \\
\hline \multirow[t]{6}{*}{ Oncogenes } & KRAS & $12 p$ & Point mutations in codon 12 & $>90$ \\
\hline & $B R A F$ & $7 \mathrm{q}$ & Point mutations & Tumors with wild-type $K R A S$ \\
\hline & $M Y B$ & $6 q$ & Amplification & 10 \\
\hline & AKT2 & $19 q$ & Amplification & $10-20$ \\
\hline & AIB1 & $20 \mathrm{q}$ & Amplification & 66 \\
\hline & HER/2-neu & $17 q$ & Overexpression & Large range \\
\hline \multirow[t]{11}{*}{ Tumor suppressor genes } & $P 16 / C D K N 2 A$ & $9 p$ & LOH+IM, HD, Meth & $>95$ \\
\hline & TP53 & $17 p$ & $\mathrm{LOH}+\mathrm{IM}$ & $50-75$ \\
\hline & $M A D 4 / D P C 4$ & $18 \mathrm{q}$ & $\mathrm{LOH}+\mathrm{IM}, \mathrm{HD}$ & 55 \\
\hline & $M K K 4$ & $17 \mathrm{p}$ & $\mathrm{LOH}+\mathrm{IM}, \mathrm{HD}$ & 4 \\
\hline & STK11/LKB1 & $19 p$ & Germline, LOH+IM & $4-6$ \\
\hline & TGF $\beta R 1$ (ALK 5) & $9 q$ & $\mathrm{HD}$ & 2 \\
\hline & TGFBR2 & $3 p$ & HD, Bi-IM & 4-7 (tumors with MSI) \\
\hline & $A C V R 1 \beta(A L K 4)$ & $12 q$ & $\mathrm{HD}, \mathrm{LOH}+\mathrm{IM}$ & 2 \\
\hline & ACVR2 & $2 q^{1}$ & Bi-IM, LOH+IM & Tumors with MSI \\
\hline & $F B X W 7$ & 4 & $\mathrm{LOH}+\mathrm{IM}$ & $<5$ \\
\hline & EP300 & $22 q$ & $\mathrm{LOH}+\mathrm{IM}$ & 25 \\
\hline \multirow[t]{4}{*}{ DNA mismatch repair } & MLH1 & $3 p$ & Germline, Meth & $3-15$ \\
\hline & BRCA2 & $13 q$ & Germline & 7 \\
\hline & $F A N C-C$ & $9 q^{1}$ & $\mathrm{HD}, \mathrm{LOH}+\mathrm{IM}$ & $<5$ \\
\hline & $F A N C-G$ & $9 \mathrm{p}$ & $\mathrm{LOH}+\mathrm{IM}$ & $<5$ \\
\hline Mitochondrial genome & Multiple & Mitochondrial DNA & $\mathrm{IM}$ & 100 \\
\hline
\end{tabular}

$\mathrm{HD}=$ homozygous mutation; $\mathrm{IM}=$ intragenic mutation; $\mathrm{LOH}=$ loss of heterozygosity; Meth = hypermethylation; $\mathrm{MSI}=$ microsatellite instability; $\mathrm{Bi}-\mathrm{IM}=$ bi-allelic intragenic mutations, usually in a poly A tract in MSI cases.

${ }^{\mathrm{a}}$ Adapted from Hruban et $a l^{7}$ courtesy of the American Registry of Pathology.

the pancreas express mucin and therefore stain with periodic acid-Schiff stain and this staining is diastase resistant. They also stain with the mucicarmine stain. Most express the cytokeratins (CK) 7, $8,13,18$ and $19 .^{7,24-26}$ CK 17 is expressed by $50 \%$ of infiltrating ductal adenocarcinoma, and CK 20 by $<20 \%$. The majority also express carcinoembryonic antigen (CEA), mesothelin, carbohydrate antigen 199 (CA 19-9), B72.3 (TAG-72), CA 125, and DUPAN $2 .{ }^{27}$ Most express MUC1 (a pan-epithelial mucin), MUC3, MUC4, and MUC5AC (a gastric foveolar mucin). ${ }^{7,26,28-32}$ A minority express MUC6 (a pyloricgland mucin), and $<10 \%$ MUC2.

The genetic alterations common in pancreatic cancer are summarized in Table 4.

\section{Pancreatic intraepithelial neoplasia}

Microscopic precursor lesions, known as pancreatic intraepithelial neoplasia, have been recognized for over a century. ${ }^{33}$ Recent molecular studies have helped solidify the importance of these lesions as precursors to invasive pancreatic cancer. PanINs are a hot topic because they suggest that it should be possible to detect and treat these non-invasive precursor lesions before an incurable invasive cancer develops. A variety of names have been given to these lesions, but in 2001 an international consensus established the 'pancreatic intraepithelial neoplasia' (PanIN) nomenclature. ${ }^{34}$ PanINs were defined as neoplastic epithelial proliferations in the smaller caliber pancreatic ducts, and PanINs were divided into three grades based on the degree of architectural and nuclear atypia present (Figure 9 and Table 5). ${ }^{34}$ Just as there is a progression in the colorectum from adenoma, to adenoma with dysplasia, to invasive cancer, so too is there a histologic and genetic progression from PanIN-1, to PanIN-2, to PanIN-3, to invasive ductal adenocarcinoma in the pancreas. ${ }^{3}$

While PanINs can involve otherwise histologically normal pancreatic parenchyma, Brune et al, have recently noted that PanINs are often, although not always, associated with a distinctive form of lobular parenchymal atrophy. ${ }^{35,36}$

PanINs are often encountered at surgical margins. ${ }^{37}$ Although there is scant evidence-based medicine to guide us, it is generally agreed that no therapy is needed for PanIN-1 or PanIN-2 at a margin. ${ }^{3}$ There have been isolated case reports of PanIN-3 lesions which progressed to invasive ductal adenocarcinomas. ${ }^{38-40}$ Therefore, the resection of additional pancreatic parenchyma to achieve a margin free of PanIN-3 may be warranted in some instances. When deciding whether or not to take an additional margin, it would be wise to consider the patient's clinical situation. If a patient has a large invasive cancer with multiple lymph node metastases, then the invasive cancer posses a significantly greater threat to their life than a PanIN-3. ${ }^{3}$ By contrast, if it is a young patient with a potentially 

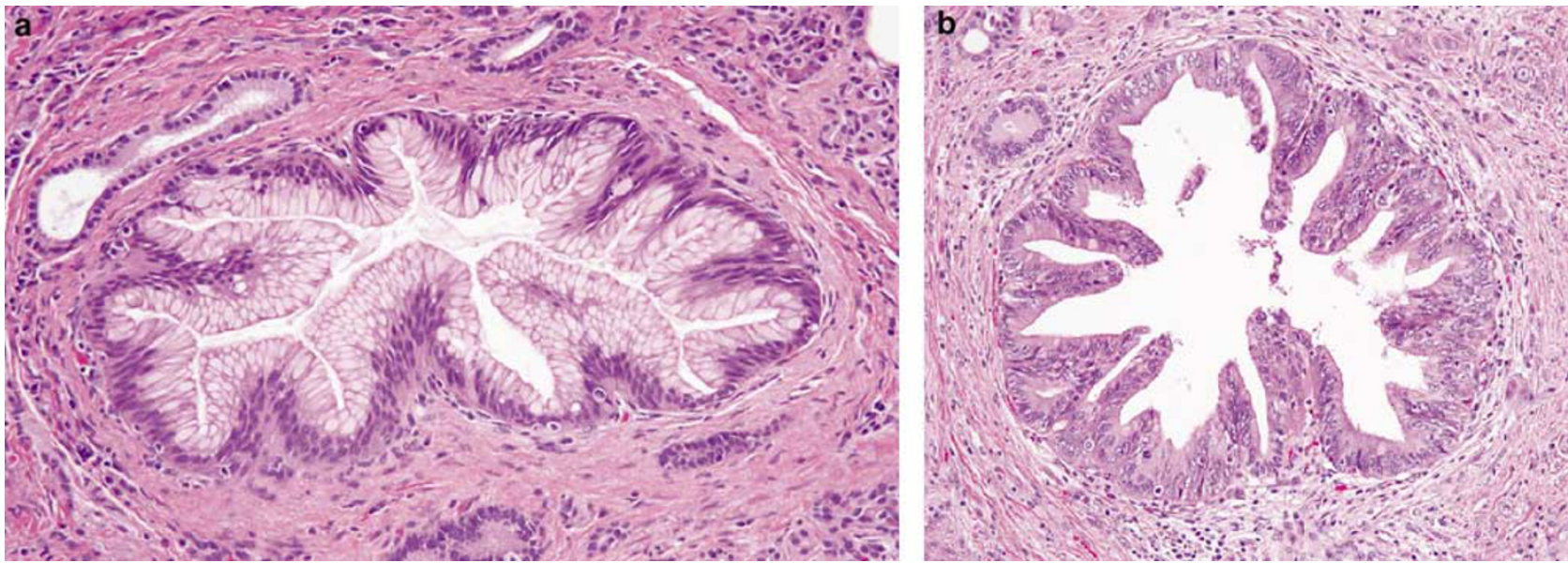

Figure 9 (a) Pancreatic intraepithelial neoplasia-2 (PanIN-2), and (b) PanIN-3.

Table 5 Existing pancreatic intraepithelial neoplasia nomenclature ${ }^{34}$

Normal: The normal ductal and ductular epithelium is a cubiodal to low-columnar epithelium with amphophilic cytoplasm. Mucinous cytoplasm, nuclear crowding, and atypia are not seen

Squamous (transitional) metaplasia: A process in which the normal cubiodal ductal epithelium is replaced by mature stratified squamous or pseudostratified transitional epithelium without atypia

PanIN-1A (pancreatic intraepithelial neoplasia 1-A): These are flat epithelial lesions composed of tall columnar cells with basally located nuclei and abundant supranuclear mucin. The nuclei are small and round to oval in shape. When oval, the nuclei are oriented perpendicular to the basement membrane. It is recognized that there may be considerable histologic overlap between non-neoplastic flat hyperplastic lesions and flat neoplastic lesions without atypia. Therefore, some may choose to designate these entities with the modifier term 'lesion' ('PanIN/L-1A') to acknowledge that the neoplastic nature of many cases of PanIN-1A has not been unambiguously established

PanIN-1B (pancreatic intraepithelial neoplasia 1-B): These epithelial lesions have a papillary, micropapillary, or basally pseudostratified architecture but are otherwise identical to PanIN-1A

PanIN-2 (pancreatic intraepithelial neoplasia 2): Architecturally these mucinous epithelial lesions may be flat but are mostly papillary. Cytologically, by definition, these lesions must have some nuclear abnormalities. These abnormalities may include some loss of polarity, nuclear crowding, enlarged nuclei, pseudo-stratification, and hyperchromatism. These nuclear abnormalities fall short of those seen in PanIN-3. Mitoses are rare, but when present are nonluminal (not apical) and are not atypical. True cribiform structures with luminal necrosis and marked cytologic abnormalities are generally not seen and, when present, should suggest the diagnosis of PanIN-3

PanIN-3 (pancreatic intraepithelial neoplasia 3): Architecturally, these lesions are usually papillary or micropapillary; however, they may rarely be flat. True cirbriforming, the appearance of 'budding off' of small clusters of epithelial cells into the lumen, and luminal necrosis should all suggest the diagnosis of PanIN-3. Cytologically, these lesions are characterized by a loss of nuclear polarity, dystrophic goblet cells (goblet cells with nuclei oriented toward the lumen and mucinous cytoplasm oriented toward the basement membrane), mitoses that my occasionally be abnormal, nuclear irregularities, and prominent (macro) nucleoli. The lesions resemble carcinoma at the cytonuclear level, but invasion through the basement membrane is absent

curable pancreatic lesion, the resection of additional parenchyma to achieve a margin free of PanIN-3 may be recommended. ${ }^{3}$

\section{Variants of adenocarcinoma}

Adenosquamous carcinoma is a malignant epithelial neoplasm with significant components of both glandular and squamous differentiation (Figure 10). ${ }^{5-7,41}$ At least $30 \%$ of the neoplasm should have squamous differentiation. ${ }^{7}$ The two components can be intimately admixed, or they can be topographically separate within the neoplasm. ${ }^{7}$ Adeno- squamous carcinoma is an extremely aggressive neoplasm. ${ }^{7}$

Colloid carcinoma is an infiltrating adenocarcinoma characterized by mucin producing neoplastic epithelial cells suspended ('floating') in large pools of extracellular mucin (Figure 11). ${ }^{5-7,41}$ The colloid component should comprise at least $80 \%$ of the neoplasm..$^{7,42}$ Most colloid carcinomas arise in association with an IPMN, and these IPMNs usually exhibit intestinal type papillae. ${ }^{7,43-45}$ Colloid carcinomas, particularly when the strict definition given above is employed, have a significantly better prognosis than ductal adenocarcinomas. ${ }^{42,44}$ Adsay et $a l,{ }^{42}$ have reported a $57 \%$ 5-year survival rate for patients with surgically resected colloid carcinomas. 


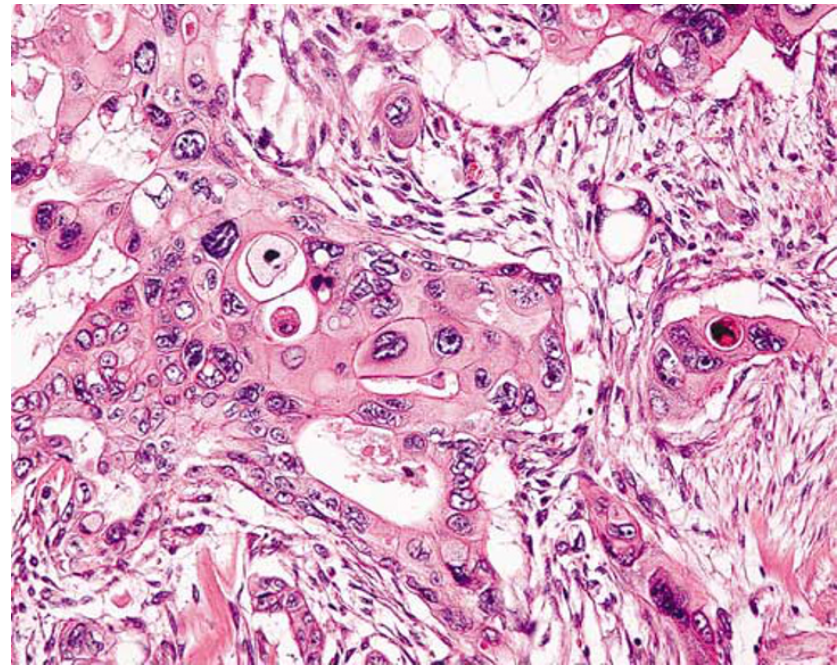

Figure 10 Adenosquamous carcinoma.

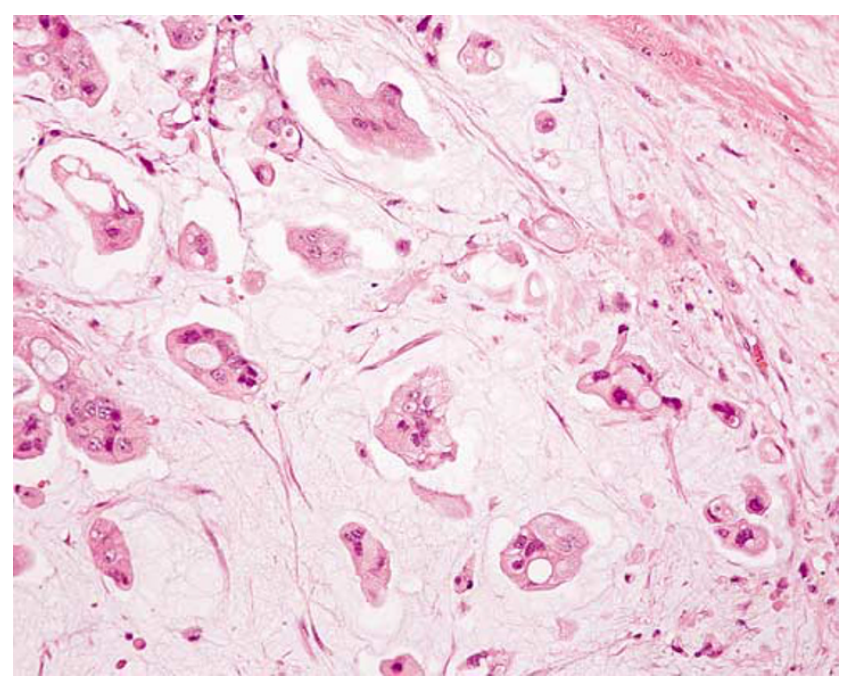

Figure 11 Colloid adenocarcinoma.

Hepatoid carcinoma is a malignant epithelial neoplasm with significant hepatocellular differentiation. ${ }^{7}$ Only a few cases have been reported and most also have areas with a more common direction of differentiation, particularly ductal adenocarcinoma. ${ }^{7,46-50}$

Medullary carcinoma is a malignant epithelial neoplasm characterized by poor differentiation, pushing borders, a syncytial growth pattern and necrosis (Figure 12). ${ }^{51,52}$ Most are microsatellite instable $(\mathrm{MSI}+)$, and immunolabeling will often reveal the loss of the expression of one of the DNA mismatch repair proteins, Mlh1 and Msh2. ${ }^{51,52}$ Patients with medullary cancers are more likely to have a family history of cancer, and some studies have suggested that these distinctive neoplasms have a better prognosis than ductal adenocarcinomas. ${ }^{51,52}$

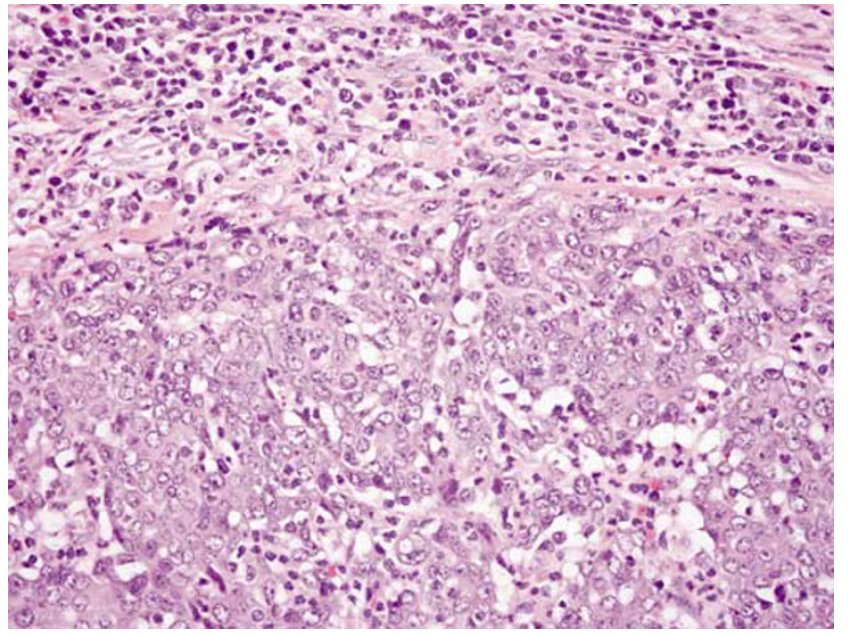

Figure 12 Medullary carcinoma with pushing boarders, poor differentiation and a syncytial growth pattern.

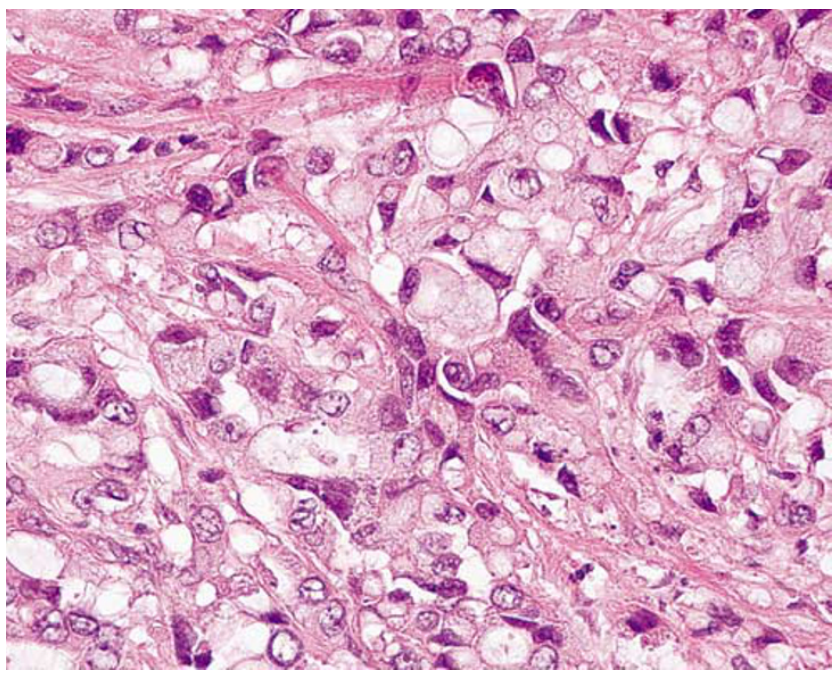

Figure 13 Signet ring cell carcinoma.

Signet ring cell carcinoma is a malignant epithelial neoplasm in which the predominant component is composed of infiltrating round non-cohesive (isolated) cells containing intracytoplasmic mucin (Figure 13). ${ }^{5-7,41}$ Metastases from a breast or gastric primary should be ruled out before making the diagnosis of a signet ring carcinoma primary to the pancreas.

Undifferentiated carcinoma is an epithelial neoplasm with a significant component showing no glandular structures or other features to indicate a definite direction of differentiation (Figure 14). ${ }^{7}$ The neoplastic cells range from pleomorphic epithelioid mononuclear cells containing abundant eosinophilic cytoplasm admixed with bizarre frequently multinucleated giant cells, to relatively monomorphic spindle cells. ${ }^{5-7,41}$ As one would expect, these are extremely aggressive almost uniformly fatal malignancies. 


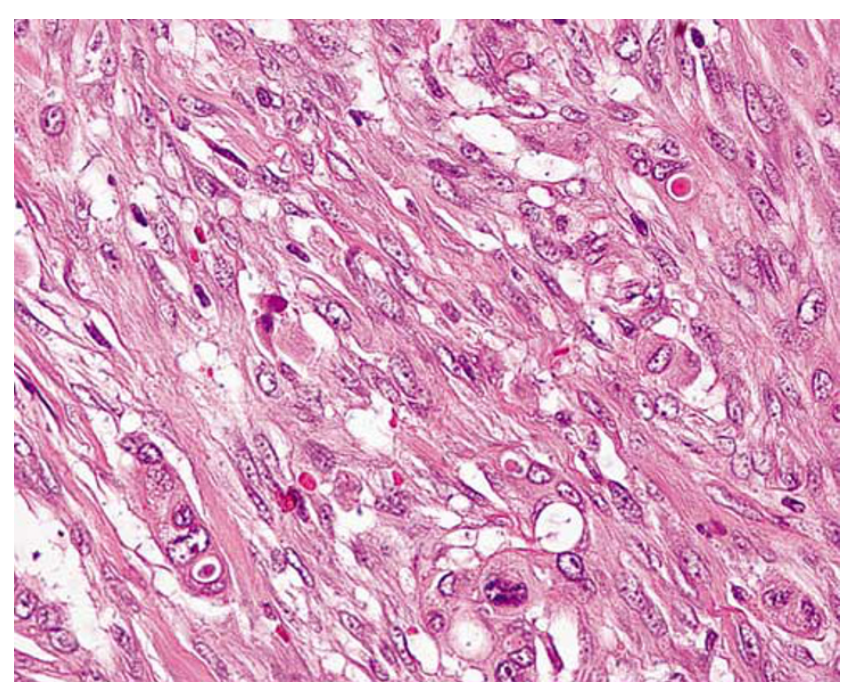

Figure 14 Undifferentiated carcinoma.

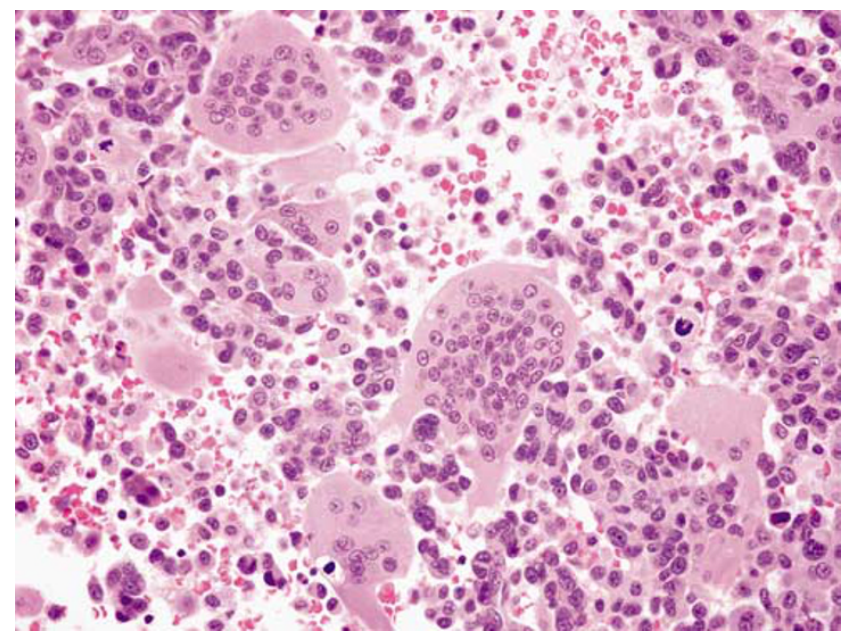

Figure 15 Undifferentiated carcinoma with osteoclast-like giant cells.

The undifferentiated carcinoma with osteoclastlike giant cells is a malignant epithelial neoplasm composed of reactive multinucleated giant cells admixed with atypical neoplastic mononuclear cells (Figure 15). ${ }^{5-7,41,53}$ These neoplasms often arise in association with an adenocarcinoma or mucinous cystic neoplasm. For years it was unclear if the osteoclast-like giant cells were malignant or reactive. Molecular analyses have demonstrated that they are reactive, while the atypical mononuclear cells are the neoplastic cells. ${ }^{53,54}$

\section{Handling of surgical specimens}

Protocols for the gross examination of pancreatic specimens and for the reporting of pancreatic neoplasms have been published by the College of American Pathologists, ${ }^{55}$ and the Association of
Directors of Anatomical and Surgical Pathology. ${ }^{56}$ While a complete review of these protocols is beyond the scope of this lecture, several points deserve highlighting. ${ }^{57}$

First, a key feature in the correct classification of cystic neoplasms of the pancreas is the relationship of the cysts to the larger pancreatic ducts. The simple act of inserting a probe into the pancreatic duct and determining if the probe passes into any of the cysts can help establish the correct diagnosis. ${ }^{57}$

Second, the duodenum, ampulla of Vater, distal bile duct and the pancreas are all included in pancreaticoduodenectomies. A single section taken parallel to the bile duct and deeply through the ampulla of Vater can help establish the relationship of a tumor to all of these structures. ${ }^{57}$

\section{References}

1 American Cancer Society. Cancer Facts \& Figures 2005. Cancer, New York: American Cancer Society 2005, pp 1-60.

2 Parkin DM, Bray F, Ferlay J, et al. Estimating the world cancer burden: Globocan 2000. Int J Cancer 2001; 94:153-156.

3 Maitra A, Fukushima N, Takaori K, et al. Precursors to invasive pancreatic cancer. Adv Anat Pathol 2005; 12:81-91.

4 Zamboni G, Klöppel G, Hruban RH, et al. Mucinous cystic neoplasms of the pancreas. In: Hamilton SR, Aaltonen LA (eds). World Health Organization Classification of Tumours. Pathology and Genetics of Tumours of the Digestive System. Lyon: IARC Press, 2000, pp 234-236.

5 Solcia E, Capella C, Klöppel G. Tumors of the Pancreas. Atlas of Tumor Pathology. Vol. Facicle 20, 3rd Series edn. Washington, DC: Armed Forces Institute of Pathology, 1997.

6 Japanese Pancreas Society. Classification of Pancreatic Carcinoma, 2nd English edn. Tokyo: Kanehara \& Co., Ltd., 2003.

7 Hruban RH, Klimstra DS, Pitman MB. Tumors of the Pancreas. Atlas of Tumor Pathology, 4th Series edn. Armed Forces Institute of Pathology: Washington, DC, 2006.

8 Matsuno S, Egawa S, Fukuyama S, et al. Pancreatic Cancer Registry in Japan: 20 years of experience. Pancreas 2004;28:219-230.

9 Lüttges J, Stigge C, Pacena M, et al. Rare ductal adenocarcinoma of the pancreas in patients younger than age 40 years. Cancer 2004;100:173-182.

10 Gold EB, Goldin SB. Epidemiology of and risk factors for pancreatic cancer. Surg Oncol Clin N Am 1998; 7:67-91.

11 Klein AP, Brune KA, Petersen GM, et al. Prospective risk of pancreatic cancer in familial pancreatic cancer kindreds. Cancer Res 2004;64:2634-2638.

12 Cubilla AL, Fitzgerald PJ. Pancreas cancer. I. Duct adenocarcinoma. A clinical-pathologic study of 380 patients. Yearbook of Pathol 1992;241-289.

13 Okusaka T, Okada S, Ueno H, et al. Abdominal pain in patients with resectable pancreatic cancer with reference to clinicopathologic findings. Pancreas 2001; $22: 279-284$. 
14 Chari ST, Leibson CL, Rabe KG, et al. Probability of pancreatic cancer following diabetes: a populationbased study. Gastroenterology 2005;129:504-511.

15 Cubilla AL, Fitzgerald PJ. Morphological patterns of primary nonendocrine human pancreas carcinoma. Cancer Res 1975;35:2234-2248.

16 Sharma S, Green KB. The pancreatic duct and its arteriovenous relationship: an underutilized aid in the diagnosis and distinction of pancreatic adenocarcinoma from pancreatic intraepithelial neoplasia. A study of 126 pancreatectomy specimens. Am J Surg Pathol 2004;28:613-620.

17 Costa J. Benign epithelial inclusions in pancreatic nerves. Am J Clin Pathol 1977;67:306-307.

18 Hirai I, Kimura W, Ozawa K, et al. Perineural invasion in pancreatic cancer. Pancreas 2002;24:15-25.

19 Nagakawa T, Mori K, Nakano T, et al. Perineural invasion of carcinoma of the pancreas and biliary tract. Br J Surg 1993;80:619-621.

20 Nakao A, Oshima K, Nomoto S, et al. Clinical usefulness of CA-19-9 in pancreatic carcinoma. Semin Surg Oncol 1998;15:15-22.

21 Takahashi S, Hasebe T, Oda T, et al. Extra-tumor perineural invasion predicts postoperative development of peritoneal dissemination in pancreatic ductal adenocarcinoma. Anticancer Res 2001;21: 1407-1412.

22 Klöppel G, Lingenthal G, von Bulow $\mathrm{M}$, et al. Histological and fine structural features of pancreatic ductal adenocarcinomas in relation to growth and prognosis: studies in xenografted tumors and clinicohistopathological correlation in a series of 75 cases. Histopathology 1985;9:841-856.

23 Adsay NV, Basturk O, Bonnett M, et al. A proposal for a new and more practical grading scheme for pancreatic ductal adenocarcinoma. Am J Surg Pathol 2005; 29:724-733.

24 Duval JV, Savas L, Banner BF. Expression of cytokeratins 7 and 20 in carcinomas of the extrahepatic biliary tract, pancreas, and gallbladder. Arch Pathol Lab Med 2000;124:1196-1200.

25 Goldstein NS, Bassi D. Cytokeratins 7, 17, and 20 reactivity in pancreatic and ampulla of vater adenocarcinomas. Percentage of positivity and distribution is affected by the cut-point threshold. Am J Clin Pathol 2001;115:695-702.

26 Lee MJ, Lee HS, Kim WH, et al. Expression of mucins and cytokeratins in primary carcinomas of the digestive system. Mod Pathol 2003;16:403-410.

27 Klimstra DS, Hameed MR, Marrero AM, et al. Ductal proliferative lesions associated with infiltrating ductal adenocarcinoma of the pancreas. Int J Pancreatol 1994;16:224-225.

28 Andrianifahanana M, Moniaux N, Schmied BM, et al. Mucin (MUC) gene expression in human pancreatic adenocarcinoma and chronic pancreatitis: a potential role of MUC4 as a tumor marker of diagnostic significance. Clin Cancer Res 2001;7:4033 -4040 .

29 Kim GE, Bae HI, Park HU, et al. Aberrant expression of MUC5AC and MUC6 gastric mucins and sialyl Tn antigen in intraepithelial neoplasms of the pancreas. Gastroenterology 2002;123:1052-1060.

30 Lüttges J, Zamboni G, Longnecker DS, et al. The immunohistochemical mucin expression pattern distinguishes different types of intraductal papillary mucinous neoplasms of the pancreas and determines their relationship to mucinous noncystic carcinoma and ductal adenocarcinoma. Am J Surg Pathol 2001;25:942-948.

31 Monges GM, Mathoulin-Portier MP, Acres RB, et al. Differential MUC 1 expression in normal and neoplastic human pancreatic tissue. An immunohistochemical study of 60 samples. Am J Clin Pathol 1999;112: $635-640$.

32 Swierczynski SL, Maitra A, Abraham SC, et al. Analysis of novel tumor markers in pancreatic and biliary carcinomas using tissue microarrays. Hum Pathol 2004;35:357-366.

33 Hulst SPL. Zur kenntnis der Genese des Adenokarzinoms und Karzinoms des Pankreas. Virchows Arch (B) 1905;180:288-316.

34 Hruban RH, Adsay NV, Albores-Saavedra J, et al. Pancreatic intraepithelial neoplasia: a new nomenclature and classification system for pancreatic duct lesions. Am J Surg Pathol 2001;25:579-586.

35 Brune KA, Abe T, Canto MI, et al. Multifocal neoplastic precusor lesions associated with lobular atrophy of the pancreas in patients having a strong family history of pancreatic cancer. Am J Surg Pathol 2006;30:1067-1076.

36 Detlefsen S, Sipos B, Feyerabend B, et al. Pancreatic fibrosis associated with age and ductal papillary hyperplasia. Virchows Arch 2005;447:800-805.

37 Hruban RH, Takaori K, Klimstra DS, et al. An illustrated consensus on the classification of pancreatic intraepithelial neoplasia and intraductal papillary mucinous neoplasms. Am J Surg Pathol 2004;28: 977-987.

38 Takaori K, Kobashi Y, Matsusue S, et al. Clinicopathological features of pancreatic intraepithelial neoplasias and their relationship to intraductal papillary-mucinous tumors. J Hepatobiliary Pancreat Surg 2003;10: 125-136.

39 Brockie E, Anand A, Albores-Saavedra J. Progression of atypical ductal hyperplasia/carcinoma in situ of the pancreas to invasive adenocarcinoma. Ann Diagn Pathol 1998;2:286-292.

40 Brat DJ, Lillemoe KD, Yeo CJ, et al. Progression of pancreatic intraductal neoplasias to infiltrating adenocarcinoma of the pancreas. Am J Surg Pathol 1998;22:163-169.

41 Klöppel G, Hruban RH, Longnecker DS, et al. Ductal adenocarcinoma of the pancreas. In: Hamilton SR, Aaltonen LA (eds). World Health Organization Classification of Tumours. Pathology and Genetics of Tumours of the Digestive System. Lyon: IARC Press, 2000, pp 221-230.

42 Adsay NV, Pierson C, Sarkar F, et al. Colloid (mucinous noncystic) carcinoma of the pancreas. Am J Surg Pathol 2001;25:26-42.

43 Seidel G, Zahurak M, Iacobuzio-Donahue CA, et al. Almost all infiltrating colloid carcinomas of the pancreas and periampullary region arise from in situ papillary neoplasms: a study of 39 cases. Am J Surg Pathol 2002;26:56-63.

44 Adsay NV, Merati K, Andea A, et al. The dichotomy in the preinvasive neoplasia to invasive carcinoma sequence in the pancreas: differential expression of MUC1 and MUC2 supports the existence of two separate pathways of carcinogenesis. Mod Pathol 2002;15:1087-1095.

45 Adsay NV, Conlon KC, Zee SY, et al. Intraductal papillary-mucinous neoplasms of the pancreas: an 
analysis of in situ and invasive carcinomas in 28 patients. Cancer 2002;94:62-77.

46 Cuilliere P, Lazure T, Bui M, et al. Solid adenoma with exclusive hepatocellular differentiation: a new variant among pancreatic benign neoplasms? Virchows Arch 2002;441:519-522.

47 Hruban RH, Molina JM, Reddy MN, et al. A neoplasm with pancreatic and hepatocellular differentiation presenting with subcutaneous fat necrosis. Am J Clin Pathol 1987;88:639-645.

48 Priesel A. Über ein ungewöhnliches Gewächs der Bauchspeicheldrüse. Virchows Arch 1928;354-362.

49 Paner GP, Thompson KS, Reyes CV. Hepatoid carcinoma of the pancreas. Cancer 2000;88:1582-1589.

50 Yano T, Ishikura H, Wada T, et al. Hepatoid adenocarcinoma of the pancreas. Histopathology 1999;35: 90-92.

51 Wilentz RE, Goggins M, Redston M, et al. Genetic, immunohistochemical, and clinical features of medullary carcinoma of the pancreas: a newly described and characterized entity. Am J Pathol 2000; 156:1641-1651.

52 Goggins M, Offerhaus GJ, Hilgers W, et al. Pancreatic adenocarcinomas with DNA replication errors (RER+) are associated with wild-type K-ras and characteri- stic histopathology. Poor differentiation, a syncytial growth pattern, and pushing borders suggest RER ${ }^{+}$. Am J Pathol 1998;152:1501-1507.

53 Westra WH, Sturm PJ, Drillenburg P, et al. K-ras oncogene mutations in osteoclast-like giant cell tumors of the pancreas and liver: genetic evidence to support origin from the duct epithelium. Am J Surg Pathol 1998;22:1247-1254.

54 Molberg KH, Heffess CS, Delgado R, et al. Undifferentiated carcinoma with osteoclast-like giant cells of the pancreas and periampullary region. Cancer 1998;82:1279-1287.

55 Compton CC, Henson DE. Protocol for the examination of specimens removed from patients with carcinoma of the exocrine pancreas: a basis for checklists. Cancer Committee, College of American Pathologists. Arch Pathol Lab Med 1997;121:1129-1136.

56 Albores-Saavedra J, Heffess CS, Hruban RH, et al. Recommendations for the reporting of pancreatic specimens containing malignant tumors. The Association of Directors of Anatomic and Surgical Pathology. Am J Clin Pathol 1999;111:304-307.

57 Westra WH, Hruban RH, Phelps TH, et al. Surgical Pathology Dissection: An Illustrated Guide, 2nd edn. Springer: New York, 2003. 